Retraction announcement about the article "Domestic violence against women: Incidence and prevalence in an emergency department population”

This article has been retracted at the request of the authors. The Publisher and the authors would like to apologize for any inconvenience caused. 


\title{
Domestic violence against women: I ncidence and prevalence in an emergency department population
}

\author{
S. Webster ${ }^{1}$, C. Pedrosa ${ }^{1}$, V. Lopez ${ }^{2}$ \\ 1. School of Nursing, Midwifery and Paramedicine, The Australian Catholic University, Australia. 2. Medical School, CMBE, \\ Australian National University, Australia.
}

Correspondence: Sue Webster. Address: 33 Berry Street North Sydney NSW 2060. Telephone: 61-297-392-387. Email:

sue.webster@acu.edu.au

Received: April 15, 2012

Accepted: June 17, $2012 \quad$ Published: November 1, 2012

DOI : 10.5430/jnep.v2n4p145

URL: http://dx.doi.org/10.5430/jnep.v2n4p145

\section{Abstract}

Objectives: A majority of women entering the hospital emergency departments and walk-in clinics in Sydney are likely to have a history of domestic violence. Domestic violence involves a physical injury, emotional and/or psychological threat by a male partner. The aim is to identify this group of women and to intervene early by referring them to counseling and other services.

Method: A prospective study was conducted to screen women of domestic violence who agreed to participate and who were accessing the Emergency Department during three months of the study period in May to July 2011. The validated Hurt Insult Threatening Screening tool (HITS) consisting of 4 questions was used. Data was analysed using descriptive statistics and two-group comparisons. The incidence and one month cumulative prevalence rates of DV were calculated with 95\% confidence interval and correlates of DV were examined.

Results: Of 239 women in Sydney, who previously sought emergency care and completed the questionnaires, 102 (47\%) had experienced threats or injuries from a current male partner in their lives. Physicians and nurses in emergency department failed to detect the history of domestic violence in women seeking treatment. Of the 239 women in the study with a male partner, $11.7 \%$ accessed the emergency room for acute domestic violence, but only $13 \%$ of these said they either told or were asked about domestic violence by the health practitioner.

Conclusion: The incidence of acute domestic violence is not as common among the women visiting the emergency department as previously reported. Although the cumulative prevalence of domestic violence is strikingly high, women who have experienced domestic violence are seldom identified by the emergency department professionals.

\section{Key words}

Women, Domestic violence, Prevalence, Emergency department

\section{I ntroduction}

One in three Australian women have experienced physical violence since the age of 15 years ${ }^{[1]}$, and almost one in five have experienced sexual violence ${ }^{[2]}$. In 2005, over 350,000 women experienced physical violence and over 125,000 women experienced sexual violence ${ }^{[3]}$. 
Domestic violence (DV) is a term that refers to a wide range of physical, sexual, emotional and financial abuse of people who have intimate partners - whether or not they are married or cohabiting ${ }^{[4]}$. Intimate Partner Violence (IPV), otherwise known as Domestic Violence, is a pattern of physical, sexual, and psychological attacks that adults use to control their intimate relationships ${ }^{[5]}$. Domestic violence is considered to be a behaviour that results in physical, social and/or psychological damage, forced social isolation, or economic deprivation which causes the victim to live in fear ${ }^{[6]}$. These behaviours are perpetrated by someone who is known to the victim ${ }^{[7]}$.

\subsection{Background of the study}

International awareness of domestic and family violence as an issue of significant social concern has increased over the past three decades. This violence knows no geographical, socioeconomic, age, ability, cultural, or religious boundaries. There is no universal national or international accepted definition of violence against women ${ }^{[8]}$.

The issue of violence and mental illness is complex and intertwined. While it is well known that exposure to violence impacts on physical health, the effects on one's mental health are less visible. Domestic violence is linked to a wide range of mental health problems including post-traumatic stress disorder (PTSD) and complex trauma, anxiety, depression and problems with alcohol and other drug use ${ }^{[9]}$. Recent research shows that the experience of having lived with a violent partner is linked to having a diagnosed psychological disorder, recent experiences of depression and anxiety and overall decreased psychological wellbeing ${ }^{[9]}$. An Australian study found that experiencing gender-based violence was significantly associated with mental health disorder, dysfunction and disability ${ }^{[10]}$. Furthermore, a high percentage of individuals using the mental health system have experienced multiple traumas ${ }^{[11]}$.

Laing ${ }^{[12]}$ has highlighted several issues for women with mental illness who are experiencing domestic violence including: their claims of abuse that are often seen as less credible and not taken seriously by health professionals due to time constraints and are quick to prescribe medication for symptoms of violence and abuse (depression and anxiety) which means that women may not have access to information and supports. However, most women who are being abused by their partner rarely disclose this problem especially whereby accessing the health care settings ${ }^{[12]}$. Barriers to disclosing abuse are both internal, such as lack of hope for change, embarrassment, fear of reprisals or disbelief, or they may be external, such as social isolation, inappropriate services, or perceptions that health professionals are unable to help or are only there for physical problems ${ }^{[4,12]}$. Confidentiality is also a concern, particularly the potential for involvement of child protection services, which may result in the woman losing custody of her children ${ }^{[4]}$.

The South Australia's study ${ }^{[13]}$ confirms that the use of EDs is estimated to be three times higher for women experiencing intimate partner violence than non-abused women. Therefore, early identification and intervention by the health professional has the potential to reduce the number of health problems associated with domestic and family violence, and lead to considerable health benefit to patients and society.

In the Australian literature, there is little emphasis on ED nursing services and their role in providing services for women with domestic and family violence issues ${ }^{[12]}$.

\subsection{Purpose of the study}

We conducted this prospective study to answer the following questions about violence against women by male partners:

1) What is the incidence of acute DV in an Emergency Department population?

2) What is the cumulative prevalence of exposure to DV, either recent or remote, in women seeking care in an ED?

3) Can clinical or demographic attributes identify women most likely to have experienced DV?

4) What proportion of women subjected to acute DV who seek care in an ED are detected by ED staff? 


\section{Subjects and method}

\subsection{Study design}

A convenience sample of all female patients visiting a busy, Emergency Department (ED) of an inner-city hospital in Sydney with 45,000 visits per year were surveyed between May to July 2011. Patients were eligible if they were at least 18 years old, fluent in English, and able to give informed consent. All clinician on-site were provided with A Handbook Dealing with Woman Abuse and the law ${ }^{[14]}$ before the study. The study was approved by the Area Health Ethnic Committee.

\subsection{Data collection procedures}

Research assistants (RAs) were trained to ensure a consistent verbal script for recruiting eligible participants. A brief invitation letter was placed in the medical charts of all adult female patients with booked appointments for follow-up and walk-in to the ED. The receptionists gave the invitations to patients when they checked in. Patients were then approached in the waiting area by the RAs. After confirming eligibility, patients were informed about the purpose and nature of the study in a separate room where they would be unaccompanied by family members or friends. Willing participants provided written consent and completed the 7-10 minute written questionnaire before seeing their clinicians. Women were assured that the completed questionnaire will remain confidential; information will not be made available to ED staff. However, after the questionnaire was completed, they were encouraged to share any concerns about personal injury or violence with the physician. In addition, the RAs offered written pamphlets concerning DV, including local resources, a health information with telephone numbers of counselors and a help line for assaulted women.

\subsection{Questionnaires}

The Hurt Insult Threaten Screening Tool (HITS) was used to screened patients for domestic violence ${ }^{[15]}$. HITS is one of the shortest validated screening tool that has been tested with diverse populations and used in family medicine practices. HITS is comprised of the following four items: (1) "How often does your partner physically hurt you?" (2) "How often does your partner insult you or talk down to you?” (3) "How often does your partner threaten you with harm?” and (4) "How often does your partner scream or curse at you?”

Patients were asked to rate their responses from 1 to 5 . Responses were summed to form an interval scale of the total HITS score, which could range from 4 to 20 . Using a cutoff score of 10.5 , Chen et al. ${ }^{[16]}$ found that HITS accurately classified $91 \%$ of non-victims and $96 \%$ of victims. HITS has a Cronbach's $\alpha$ of 0.80 and is highly correlated with the Conflict Tactics Scales $(r=0.85){ }^{[16,17]}$. In our study the Cronbach's $\alpha$ of 0.76 .

The survey consisted of three sections: socio-demographic, health-related variables, and patients' experiences of IPV. While the first and second sections applied to all participants, the IPV section applied only to those in current or recent intimate relationships. The term "intimate partner" referred to a spouse, common-law partner, or boyfriend. A recent relationship was defined as an intimate relationship of at least one month’ duration during the last year.

\subsubsection{I ncidence and prevalence of DV and I PV}

The incidence of DV was determined to an answer of yes or unsure to one or both of the following questions: 'Are you here today for injuries from your male partner?' or 'Are you here today because of illness or stress related to threats, violent behaviour, or fear from your male partner?' To avoid under estimating the incidence of acute DV, we included 'unsure' as a positive response to the item. Only women with current male partners were asked these two questions.

To determine the cumulative prevalence of DV, questions were asked about any DV episodes with current or past male partners. The cumulative prevalence of DV was determined as a positive or unsure answers to either of the questions 
(above) pertaining to acute DV or a positive answer to one or more of the following questions about current male partners: If this had happened within one month, women were considered to be positive for one month prevalence.

\subsubsection{Experiences of I PV}

Experiences of IPV were assessed using HITS scales, along with questions recommended in Ramsay et al.'s study ${ }^{[18]}$ about health care professionals screening of domestic violence. The study also examines emotional and physical violence and threat of violence. Emotional IPV was the response to: (1) partner's jealousy; (2) controlling; (3) isolation from family or friends; and (4) insults. Threat of IPV was assessed by responses to: (1) fear of disagreeing with partner; and (2) feeling physically threatened by partner or otherwise physically hurt; and being forced to have unwanted sex. Patients were asked to respond either "yes" or "no" to each question. We determined participants as IPV victims if they responded "yes" to at least two items on emotional violence or one item on threat of violence or physical violence.

\subsubsection{Attitudes toward screening for DV}

Attitudes toward the screening were assessed using the four attitude domains: (1) patient-perceived benefits for quality of medical consultation; (2) means of achieving them, (3) privacy-barriers, which covered patients' concerns about information privacy; and (4) interaction-barriers, which meant concerns about interference during interactions with physicians.

\subsection{Data analyses}

Data was analysed using descriptive statistics and two-group comparisons. The incidence and one month cumulative prevalence rates of DV were calculated with 95\% confidence interval (CIs) and correlates of DV were examined. Associations between demographic variables and incidence and cumulative prevalence rates of DV were tested using Student's $t$ test for continuous variables and $x^{2}$ for categorical variables. Data were analyzed using the Statistical Package for the Social Sciences, version $20^{[19]}$.

\section{Results}

\subsection{Socio-demographic characteristics}

Participants had a mean age of 33.3 years (range, 19 to 66); 75\% of them were in current or recent relationships (see Table 1). About $36 \%$ were immigrants, and 59\% of these had lived in Australia for more than 20 years. Most participants had at least some university education and were currently employed. They rated their health as "good" with a mean score of 3.2 ( $\mathrm{SD} \pm 1$ ) on a scale of 1 to 5 . They had visited family physicians during the past year a mean of 4.6 times (range 0 to 30 ).

Table 1. Socio-demographic characteristics $(\mathrm{n}=239)$

\begin{tabular}{|c|c|c|}
\hline Variable & $\mathbf{N}$ & $\%$ \\
\hline Marital status & 239 & \\
\hline - $\quad$ Married & & 54.6 \\
\hline - $\quad$ Separated, divorced, or widowed & & 13.9 \\
\hline - $\quad$ Single, in current relationship & & 20.3 \\
\hline - $\quad$ Single, not in relationship & & 11.4 \\
\hline Had children & 113 & 56.2 \\
\hline Country of birth & & \\
\hline - $\quad$ Australia & & 63.9 \\
\hline - $\quad$ Outside Australia & & 36.1 \\
\hline
\end{tabular}

(Table 1 continued on page 149) 
Table 1. (Continued.)

\begin{tabular}{|c|c|c|}
\hline Variable & $\mathbf{N}$ & $\%$ \\
\hline If an immigrant, years lived in Australia & 170 & \\
\hline - $\quad<10$ & & 23.9 \\
\hline - $10-20$ & & 16.9 \\
\hline - $\quad>20$ & & 59.2 \\
\hline If an immigrant, country of birth & 170 & \\
\hline - $\quad$ Europe & & 36.8 \\
\hline - $\quad$ East, Southeast & & 39.1 \\
\hline - $\quad$ South East Asia & & 9.2 \\
\hline - $\quad$ Arabia, West Asia & & 6.6 \\
\hline - $\quad$ Africa & & 4.1 \\
\hline Education & 239 & \\
\hline - $\quad$ Less than high school & & 3 \\
\hline - High school & & 19.9 \\
\hline - University & & 55.7 \\
\hline - $\quad$ postgraduate & & 21.4 \\
\hline Employment Status & 239 & \\
\hline - $\quad$ Full-time & & 49.8 \\
\hline - $\quad$ Part-time & & 14.4 \\
\hline - Unemployed & & 13.9 \\
\hline - $\quad$ Retired or disability & & 21.9 \\
\hline Household income (\$) & 181 & \\
\hline - $\quad<30000$ & & 15.5 \\
\hline - $\quad 30000-50000$ & & 19.9 \\
\hline - $\quad 50000-70000$ & & 20.5 \\
\hline - $\quad>70000$ & & 44.2 \\
\hline
\end{tabular}

\subsection{Prevalence of DV}

The total of 265 women who presented at the ED for care during this period, of these women, 239 completed the questionnaire (90\%), 113 women who completed the questionnaire declined participation with further questioning. This group was older than 102 participants group, with median age of 38 years [range, 19 -75]. One hundred and two (47\%) women reported having been threatened or physically injured by a husband or boyfriend at some time in the last year (cumulative prevalence, 52.2\%; CI - 52.2\%) (see Table 3). Women who were with a current male partner were 24 (11.7\%) (95\% CI - 8.7\% to 15.2\%). Only 11 (23\%) of these women screened with acute DV presented for care because of trauma, 6 (13\%) either told staff about DV or were asked about DV by ED professionals. Among 102 women without current male partners, 13 (5.6\%) reported an episode of DV within the previous one month and 28 (28.5\%) reported within previous one year. For the entire sample, the cumulative lifetime prevalence of DV exposure was 54.2\% (95\% CI - 50.2\%).

\subsection{Experiences of I PV}

Of 102 respondents to the IPV section, 29 women reported at least one experience of violence, 18 of those perpetrated by current partners; 10 by recent partners; and one by current and recent partner. Using our IPV case definition, the prevalence of emotional IPV was 10.4\% (95\% CI - 5.4 to 15.4), threat of IPV was 8.3\% (95\% CI - 3.8 to 12.8), and physical or sexual IPV was 7.6\% (95\% CI - 3.3 to 11.9) (see Table 2). Many patients who reported emotional IPV also reported threat of IPV (60\%, Fisher's exact test: $P \leqslant .001$ ) or physical IPV (53\%, Fisher's exact test: $P \leqslant .001)$. Counting IPV victims only once across three types of IPV the overall prevalence was $14.6 \%$ (95\% CI - 8.8 to 20.3). Comparison of victims and non-victims of IPV showed that victims had lower household incomes ( $t=2.1, \mathrm{~d} f=131, P<.01$ ), but were similar in other socio-demographic and health-related variables, including comfort level with completing the survey and Australian-born versus immigrant status. 
Table 2. Responses to questions on intimate-partner violence (IPV) in current or recent relationships ( $\mathrm{N}=102)$ : Overall, 21 respondents (prevalence was 14.6\%) reported being victims of violence (victims were counted once across the 3 types of violence).

\begin{tabular}{|c|c|c|}
\hline Questions & $\mathbf{N}=102$ & $\begin{array}{l}\text { \% of respondents } \\
\text { Saying 'Yes' } \\
(9.5 \% \text { CI })\end{array}$ \\
\hline \multicolumn{3}{|l|}{ Emotional Violence* } \\
\hline - Is your partner very jealous? & 14 & $7.6(3.3-11.9)$ \\
\hline - Does your partner try to control your life? & 16 & $10.4(5.4-15.4$ \\
\hline - $\quad$ Does your partner try to keep you away from family and friends? & 12 & $6.3(2.3-10.3)$ \\
\hline - Does your partner insult you or put you down? & 22 & $12.5(7.1-18.0)$ \\
\hline - Pooled responses of those saying 'yes' to 2 or more items in the emotional domain & 10 & $10.4(5.4-15.4)$ \\
\hline \multicolumn{3}{|l|}{ Threats } \\
\hline - $\quad$ Are you afraid to disagree with your partner? & 12 & $6.3(2.3-10.3)$ \\
\hline - Do you feel physically threatened by your partner? & 8 & $4.9(1.4-8.4)$ \\
\hline - Pooled responses of those saying "yes" to feeling of threat & 6 & $8.3(3.8-12.8)$ \\
\hline \multicolumn{3}{|l|}{ Physical or sexual violence } \\
\hline - Has your partner ever pushed, hit kicked, or otherwise physically hurt you? & 9 & $5.6(1.8-9.4)$ \\
\hline - Has your partner ever forced you to have sex when you did not want to? & 9 & $5.6(1.8-9.4)$ \\
\hline - Pooled responses of those saying 'yes' to any aspect of physical or sexual violence & 5 & $7.6(3.3-11.9)$ \\
\hline
\end{tabular}

Note: Each item is scored from 1 to 5 . Scores for this study ranged from 4 to 20 . A score greater than 10 is considered positive. * 17.4\% of respondents reported at least 1 experience of emotional violence (95\% CI 11.2-23.6)

Table 3. Domestic Violence Incidence among women with a male partner $(\mathrm{N}=239)$

\begin{tabular}{llll}
\hline Questions & Yes & Unsure & No \\
\hline $\begin{array}{l}\text { *Are you here today because } \\
\text { of illness or stress related to } \\
\text { threats, violent behaviour, or }\end{array}$ & 196 & 21 \\
fear from your husband, & & \\
partner or boyfriend? & & 13 \\
*Are you here today for \\
$\begin{array}{l}\text { injuries from your husband or } \quad 9 \\
\text { boy friend? }\end{array}$ \\
\begin{tabular}{l} 
Total \\
\hline
\end{tabular}
\end{tabular}

*number indicate: number of women who responded to the questions. Numbers are mutually exclusive. 'Unsure' responses include only those women who answered 'unsure' to both of the preceding questions

\subsection{Correlates of DV}

Of the 239 women who had been threatened or physically injured by a partner at some time in their lives, the cumulative prevalence was $54.2 \%$; $95 \%$ CI, - 50.2\% to 58.1\%) (see Table 4). There was no significant association between a history of DV and ethnicity. Several correlates of DV exposure (cumulative prevalence) were identified. Eighty one percent (81\%) of women with a history of suicide attempts had experienced DV at some time in their lives, compared with $19 \%$ of those with no history of suicide attempts $(P<.001)$. This concurred with prior study that women exposed to acute or prior DV were more likely than unexposed women to have made suicide attempts and to report excessive ethanol use ${ }^{[5,8,9]}$. 
Table 4. Rates of Domestic Violence among women in Emergency Department

\begin{tabular}{lll}
\hline Type of Violence & No (\%) & 95\% Confidence Interval \\
\hline Acute DV incidence & $29(11.7)$ & $8.7-15.3$ \\
DV of current partner & $32(32.6)$ & $23.4-32.3$ \\
1-mo prevalence (102) & $13(11.9)$ & $9.5-14.6$ \\
1-y prevalence (239) & $28(15.3)$ & $12.6-18.3$ \\
Cumulative prevalence (239) & $129(54.2)$ & $50.2-58.1$ \\
\hline
\end{tabular}

*Numbers in brackets indicate number of respondents

\section{Discussion}

Domestic violence takes many forms ranging from homicide, rape, and battering to threats of violence, verbal assaults and other forms of intimidation. It is an incontrovertible fact that DV represents an important health threat to women. This is the first study in our hospital reporting on the prevalence of IPV among female patients visiting the ED. The results highlighted that if a clinician sees 150 patients a week, half of whom are women in relationships; our prevalence rate of $14.6 \%$ implies that a physician is likely to see 11 victims of IPV every week. Given this high prevalence and women's reluctance to disclose, clinicians need to be highly vigilant to screen cases of IPV.

Clinicians in hospital could be pivotal in detecting IPV and offering empathy, support, and referral to helping agencies ${ }^{[20,21]}$. Studies report that the risk of anxiety, depression, suicide attempts, and symptoms of posttraumatic stress disorder is much lower among women suffering from IPV if they have strong social support ${ }^{[4]}$. Forty five women who contacted advocacy services report that concerned nurses and physicians motivated them to seek help ${ }^{[11]}$. Longitudinal research indicates that referral to specifically tailored counseling services benefits victims of abuse by helping them learn to reduce emotional or physical abuse and improving their quality of life. Clinicians could empower abused women by promoting social support, self-worth, and internal locus of control, decision making, and use of counseling services.

This study is especially important for abused women as specific inquiries by health care providers give them permission to disclose when completing surveys, and patients are likely to learn more about, and reflect on their risk before they see their physicians. Future research should examine the actual use of screening by patients and providers and assess its effectiveness in primary practice.

Inquiring about emotional IPV is important. We found strong correlations between emotional and physical IPV. Traditionally, researchers and clinicians have focused on screening for physical violence, but emotional abuse is part of a larger pattern of domination and control. Emotional abuse precedes physical abuse or has consequences as damaging as physical abuse asking about emotional IPV would help in early detection and timely management of risk, so clinicians and health educators need to broaden their current definition of IPV. Screening can provide a form of primary prevention within the community ${ }^{[12]}$, as well as secondary prevention if adequate support services are in place.

\subsection{Limitations}

We acknowledge that our sample is small and results might have limited generalisability because the study was conducted in only one hospital. This hospital, however, had several clinicians on staff and served a large number of diverse patients' groups. However, we recruited patients with a variety of reasons for the ED visits including all three shifts to increase generalisability. The study had a high response rate, and reassuringly, participants were similar to women residing in Sydney in terms of immigration and marital status. The results, therefore, can likely be generalised to similar practice. Our rates of IPV, however, might underestimate the real magnitude due to under-reporting. 


\subsection{I mplications for practice}

The results of the study demonstrated that DV is not a common presenting complaint among women visiting EDs; however, clinicians do not detect most women at risk of DV. The data presented here supported the recommendations of the Consumer Advisory Group for Mental Health to improve methods of detection, counseling and referral for DV in emergency settings. Provider reluctance to ask about abuse is a significant barrier to patient disclosure of domestic violence ${ }^{[16]}$, although other factors may also interfere with this process ${ }^{[10]}$. Early identification and intervention by the health system may reduce health problems associated with domestic and family violence and lead to savings for the health sector.

\section{Conclusion}

This study shows significant rate of IPV among women and the need for all clinicians to be vigilant. This implies both complex and serious issues relating to domestic and family violence, which, without the screening program, may have never been addressed by the ED nurses. Thus, at the micro level, this implies an improved service for women. Future research should examine ways to help ED nurses and physicians inquire into IPV and conflict in relationships.

\section{Acknowledgement}

The study was funded by the Violence Prevention Coordination Unit for Women’s Policy Department of Premier and Cabinet New South Wales, Australia.

\section{References}

[1] Australian Bureau of Statistics, Personal Safety Survey. Australian Institute of Criminology, Homicides Resulting from Domestic Altercations, Crime Facts Info. 2005; 22.

[2] Moussos, J. and T. Makkai. Women's experiences of male violence findings from the Australian component of the International Violence Against Women Survey (IVAWS), Australian Institute of Criminology. 2004.

[3] National Council to Reduce Violence against Women and their Children. NSW Government: Canberra. 2009a.

[4] Feder, G., Huston, M., Ramsay, J., Taket, AR. Women exposed to intimate partner violence: expectations and experiences when they encounter health care professionals: a meta-analysis of qualitative studies. Arch Intern Med. 2006 ; 166 (1): $22-37$. PMid:16401807 http://dx.doi.org/10.1001/archinte.166.1.22

[5] NSW Health. New South Wales: Mothers and Babies [Internet]. 2007, NSW Department of Health, Sydney. 2010. Available from: http://www.publish.csiro.au/nid/227/issue/5809.

[6] O’Leary KD. Psychological abuse: a variable deserving critical attention in domestic violence. Violence Victoria, Australia. 2010; 14 (1): 3-23.

[7] Tiwari, A., Leung, WC., Leung, TW., Humphreys, J., Parker, B., Ho, PC. A randomized controlled trial of empowerment training for Chinese abused pregnant women in Hong Kong. BJOC. 2005; 112 (9): 1249-56.

[8] Loxton, D, Schofield, M and Hussain, R. Psychological Health in Midlife Among Women Who Have Ever Lived with A Violent Partner or Spouse. Journal of Interpersonal Violence. 2006; 21: 1092. PMid:16829669 http://dx.doi.org/10.1177/0886260506290290

[9] Rees et al. 'Lifetime Prevalence of Gender-Based Violence in Women and the Relationship with Mental Disorders and Psychosocial Function’ Journal of the American Medical Association. 2011; 306 (5): 213-216. PMid:21813429 http://dx.doi.org/10.1001/jama.2011.1098

[10] National Council to Reduce Violence against Women and their Children. Time for action: The National Council’s Plan for Australia to Reduce Violence against Women and their Children, 2009_2021. 2009; Canberra: The Department of Families, Housing, Community Services and Indigenous Affairs.

[11] Laing, L., Toivonen, C, Irwin, J and Napier, L. “They never asked me about that”: Stories of Women who experience Domestic Violence and Mental Health Concerns/Illness, A report from the research project: Towards Better Practice: Enhancing Collaboration between domestic violence and mental health services. 2010. University of Sydney, Faculty of Education and Social Work. Available from: http://ses.library.usyd.edu.au/bitstream/2123/6535/1/They\%20never\%20asked\%20me.pdf 
[12] Koziol-McLain, J., Giddings, L., Rameka, M., \& Fyfe, E. Intimate partner violence screening and brief intervention: Experiences of women in two New Zealand health care settings. Journal of Midwifery and Women's Health. 2008; 53: 504-510. http://dx.doi.org/10.1016/j.jmwh.2008.06.002

[13] Power, C., Parry, Y. An evaluation of Flinders Medical Centre Emergency Department family violence screening program. Adelaide, South Australia: 2007; Flinders University, Southern Adelaide Health Service.

[14] Chisholm, R. "Simplifying the Family Law Act: saying less and saying better". 2011; 21 (3): 11-15. Australian Family Lawyer.

[15] Sherin, K M. Sinacore, JM. Li, XQ, et al. HITS: A Short Domestic Violence Screening Tool for Use in a Family Practice Setting. Fam Med. 1998; 30 (7): 508-12. PMid:9669164

[16] Chen PH, Rovi S, Vega M, Jacobs A, Johnson MS. Screening for domestic violence in a predominantly Hispanic clinical setting, Fam Pract. 2005; 22(6): 617-623. PMid:16055473 http://dx.doi.org/10.1093/fampra/cmi075

[17] Stuart, P. A Stitch in time: Validation of the domestic violence identification tool. Adelaide: Commonwealth of Australia, Government of Australia-Department of Human Services, Partnerships against Domestic Violence. 2009.

[18] Ramsay J, Richardson J, Carter YH, Davidson LL and Feder, G. Should health professionals screen women for domestic violence? Systematic review, British Medical Journal. 2002; 325 (7359): 314-326. PMid:12169509 http://dx.doi.org/10.1136/bmj.325.7359.314

[19] SPSS Inc. SPSS for Windows. Version 20 edition 2011. Chicago, Illinois, USA.

[20] Sackett, LA., Saunders, DG. The impact of different forms of psychological abuse on battered women. Violence Vict. 2009; 14(1): 105-19. 